\title{
Attitude towards sexual control among women in conjugal union in the era of the HIV/AIDS epidemic in Mahikeng, South Africa
}

\author{
Godswill N. Osuafor and Akim J. Mturi \\ Research Niche Area 'Population and Health', Faculty of Human and Social Sciences \\ North West University (Mafikeng Campus) \\ akimmturi@gmail.com
}

\begin{abstract}
Husbands continue to be the greatest source of sexually transmitted infections including HIV to their wives. Using a survey of 568 respondents and 33 in-depth interviews, this study examined the attitudes of women in marital and steady relationships towards sexual control in Mahikeng. Data analysis using logistic regression showed that age, type of union, education, occupation, and number of living children were significantly associated with attitudes towards rejecting sex. Additionally, age, type of union, education, and number of living children were found to be significantly associated with demand for sex. Qualitative data revealed that social-cultural factors influence the disposition of most women regarding demanding or rejecting sex from their husbands. Their attitudes to sexual control are intertwined with cultural, religious belief and perception that husbands have sexual right over their wives. Women empowerment initiatives should continue to be considered as a means to assist women to control their sexuality.
\end{abstract}

Keywords: Sex; Sexual control; HIV/AIDS; sexually transmitted infections; South Africa

\section{Résumé}

Les maris (hommes) continuent à être la principale source d'infections sexuellement transmissibles (STD) y compris le VIH à leurs épouses. Un échantillon de 568 femmes a été interviewé lors de 33 entrevues pour évaluer leur attitude face aux relations conjugales et la maîtrise sexuelle dans Mahikeng, Afrique du Sud. L'analyse des données par régression logistique a montré que l'âge, le type d'union, l'éducation, la profession et le nombre d'enfants vivant était significativement associée aux attitudes envers le rejet du sexe. En outre, l'âge, le type d'union, l'éducation, et le nombre d'enfants ont été significativement associés à la demande pour le sexe. Les données qualitatives ont révélé que les facteurs socio-culturels influencent la disposition de la plupart des femmes en matière d'exiger ou de rejeter le sexe de leurs maris. Leurs attitudes à l'égard au contrôle sexuel sont étroitement liées avec la croyance religieuse, culturelle et la perception que les maris ont le droit sexuelle sur leurs femmes. L'initiative de la promotion et responsabilisation sociale des femmes doivent être considérées comme un moyen d'aider les femmes à contrôler leur sexualité.

Mots clé: sexe; contrôle sexuelle; le VIH / sida; les infections sexuellement transmissibles; I'Afrique du Sud

\section{Introduction}

Marriage' takes place to formalize sexual relationship of couples. A couple can choose to have a civil (or Christian) and customary (or traditional) marriage in South Africa. Whilst the civil marriage is a straight forward exercise involving getting a marriage certificate from the government (i.e. the Department of Home Affairs), the customary marriage is a process which can take a short

\footnotetext{
${ }^{1}$ This paper deals with only opposite sex marriages.
}

duration of few weeks or as long as ten years or more. Common to Black South Africans, customary marriage is concluded by payment of lobola (bride price) which symbolizes the joining of the two (bride and groom) families (Peart, 1983). Many couples still go to the government after payment of lobola to get a marriage certificate, but some decide to get a marriage document from the Chief. Cohabitation happens when a man and a woman decide to live together like a husband and wife but do not have a legal document. Cohabiting relations are generally 
accepted in South Africa (Matshidze et al., 1998; Swart-Kruger \& Richter, 1997; Mindry et al., 201 I). For the purpose of this paper, married and cohabiting women are studied together because they have more or less similar experiences on sexual control.

The main purpose of this paper is to assess the attitudes toward sexual control among currently married or cohabiting women. It is very important to understand the extent to which women in stable sexual relationships are able to negotiate for matters pertaining to their sexuality in this era of the HIV/AIDS epidemic. The factors related to sexual control of these women are also investigated. The specific objectives are to explore about knowledge on STls transmission and prevention methods; to examine the extent of women's control over sex with their husbands/partners; to investigate the justification women give for their position on having or not having sexual control; and to analyze the factors related to women's attitudes toward having sexual control.

\section{Literature Review}

Gender equality was the expectation for the South African socio-political environment with the demise of apartheid. However, studies have shown that culture and patriarchal values (Jewkes et al., 1999; Morrell, 1998; Hargreaves et al., 2009; Mogale et al., 2012) continue to shape reproductive attitudes and behaviour in South Africa. Jewkes et al. (1999) reported the cultural acceptability that a man owns his wife when he pays lobola. Thus, the perception of women as men's property compromises their power in decision-making on sexual and reproductive health matters. Culturally accepted norms in marital relationships with regards to roles of men and women certainly contribute to poor sexual negotiation (Orisaremi \& Alubo, 2012; Balmer et al., 1995).

Concerns about married women's control over their sexuality were reverberated by the HIV/AIDS epidemic in developing countries. The higher susceptibility of women to sexually transmitted infections (STIs) including HIV has been attributed to the African patriarchal norms of men dominating family decision-making and biological vulnerability of women (Magadi, 20I I; Ackerman \& de Klerk, 2002; Coombs et al., 2003; Phyllis, 2013). Given the tempo of the HIV/AIDS epidemic in South Africa, understanding the extent social values influence the vulnerability of women to HIV infection in marital 539 relationships carries some sense of urgency. It has been shown also that married women in Africa are becoming infected with HIV at higher rates than single, sexually active young women of the same age (Glynn et al., 200I). Ogunjuyigbe and Adeyemi (2005) documented that women who took part in their qualitative study lamented that they are being infected with STIs by their husbands. These findings suggest that women do not have the control over their sexual lives even with threats of infidelity in sexual relationships (Schoepf, 1992; Langen, 2005; Varga \& Makubalo, 1996). The alluded powerlessness of women in sexual control seems to be entrenched in protracted cultural tenets (Langen, 2005; Jewkes et al., 1999; Jewkes \& Morrell, 2010), socio-economic dependency on men and limited education to women (Wodi, 2005; Ackerman \& de Klerk, 2002; Mindry et al., 20I I).

Studies in some African countries have shown mixed reports on the ability of women to control their own sexual lives. Awusabo-Asare et al. (1993) reported that married women have limited control over their sexuality in Ghana despite the fact that tradition accorded them sexual rights. They found that $60 \%$ of the women felt that they did not have right to refuse sex. In addition, poor control over sexual lives was exacerbated among women with no formal education. Awusabo-Asare and his colleagues concluded that inability of women to refuse sex was on the premises that male fidelity is not a cultural expectation. On the contrary, the findings in Nigeria revealed that women have considerable control over their sexuality especially when there is evidence of infidelity and disease infection (Orubuloye et al., 1993; Ogunjuyigbe \& Adeyemi, 2005; Wusu \& Isiugo-Abanihe, 2008). It was observed that increasing ability of women to exert controls on their sexual lives was associated with their economic independence.

Socio-economic dependency of women on men has uncompromisingly conferred on men the decision-making power in reproductive issues and may continue to be a challenge to women's sexual control (Jewkes \& Morrell, 20I0; Mindry et al., 20II). Financial dependence on men was the reason for uneducated and jobless women in Cape Town (South Africa) to remain in a relationship that tramples on their sexual dispositions (Mathews \& Abrahams, 200I). It was also found in KwaZuluNatal (South Africa) that women's ability to negotiate sex was incapacitated because of poor 
education (Langen, 2005; Varga, 2003). These give credence to economic status of women as the determinant of their bargaining power in sexual issues (Folbre, 1986; McElroy, 1990).

There are studies that contradict the relevance of economic independence in enhancing sexual control and sexual decision-making of women. For instance, ownership of income generating ventures did not improve women's bargaining power in reproductive decision-making in Ibadan, Nigeria (Odebode, 2004). Another study showed that possession of economic assets by women may not increase their control power in reproductive decision-making (Omeje et al., 20ll). In fact, economic independency of women led to their spouse relinquishing financial responsibilities in the household without any effect on sexual empowerment (Odebode, 2004; Nyanzi et al., 2005). Nyanzi et al. (2005) concluded that economic independence of women only avails them greater opportunity to enter and exit relationships than their counterparts who are not economically independent. This suggests that the economic status of women may not entirely explain the inequality in sexual negotiation and sexual decision-making in marriage.

\section{Data source and Methods}

The study uses a mixed methods approach. The survey was carried out in Mahikeng municipality, where the capital city of the North-West province of South Africa is located between May and July, 2012. North-West is the fourth province with the highest HIV prevalence and people living with HIV/AIDS in South Africa (Department of Health, 20II). The majority of people in Mahikeng are Tswana speakers who have patriarchal culture and traditions towards marriage and other sexual matters. However, Tswana marriage system like other African societies has undergone profound transformation due to westernization. But some scholars still argue that culture continues to be an important force in daily life of Tswana people particularly in rural areas (Nkomazana, 2008; Gulbrandsen, 1986). So this area is a perfect setting for investigating how married women feel about their culture and traditions on sexual matters against religious teachings and westernization. In addition, Mahikeng municipality is one of the few places in the North-West province which has a large urban setting $(25 \%$ of the area) surrounded by various rural areas $(75 \%)$.
The sampling frame for each of the selected areas consisted of the enumeration areas provided by Statistics South Africa (20I2). These enumeration areas were treated as clusters. The clusters from both rural and urban areas were sampled with probability proportional to size. A total of 800 households were randomly selected from the selected clusters. A structured questionnaire was developed and pretested before administering to 600 eligible respondents identified from the households in those clusters. A total of 568 married or cohabiting women aged 18-49 years (i.e. $95 \%$ response rate) filled in the questionnaire. For details on the sampling design see Osuafor (20/4). Fieldworkers were students registered at the North-West University (Mafikeng Campus) under the population studies and social work programmes. There was training and pilot study before fieldworkers were dispatched to the field.

Most of the variables used in the analysis were obtained from direct responses from the questionnaire. However, aggregate knowledge about HIV was created by asking women the various ways of HIV transmission and prevention in addition to a number of misconceptions including: whether a healthy person can have HIV/AIDS; whether HIV can be transmitted through mosquito bites, supernatural means or through food. Respondents who were able to identify sexual intercourse, mother to child transmission at delivery or through breastfeeding as ways of HIV transmission and condom use as a method of HIV prevention in addition to rejecting all the four misconceptions were recorded as having comprehensive knowledge. Women were classified as having moderate knowledge if they were able to identify condom use as one of the ways of HIV prevention and sexual intercourse, mother to child transmission or breastfeeding as possible ways of HIV transmission in addition to rejecting at least two of the misconceptions while little knowledge was classified as knowledge of only one method of HIV transmission and rejecting of at least one misconception or none. Furthermore, women who did not know any method of HIV transmission or prevention and failed to reject any of the misconceptions were classified as having no knowledge on HIV/AIDS.

Quantitative data were analysed by using both descriptive and multivariate statistical techniques. At multivariate stage, the logistic regression models were used to determine the predictors of respondents' opinion on married women's demand 
for sex and rejection of sexual intercourse from husbands or partners. The logistic regression was used because both dependent variables are dichotomous in nature.

For the qualitative study, individual in-depth interviews (IDIs) were conducted on the experiences regarding to sexual control. The study employed phenomenological approach (Jerrett 1994). This approach is concerned with the study of experiences from the perspective of the individual. Hence there is no single reality. Given that sex is a conservative matter in an African setting, only individuals who are willing to describe their experience in sexual control were interviewed. The study also aimed at interviewing women with different background characteristics such as place of residence, age, duration of union, education and occupation. Since questions asked have much to do with women's experience in marriage, only women who were married for at least five years were considered. In all, 33 women in marital/cohabiting union participated in the IDIs. Interviews were conducted using a semi-structured interview guide. Information from IDIs, which was collected in Setswana, was transcribed and translated to English and organized under broad headings that depict different aspects of the thematic area manually. Content analysis was used to analyse the qualitative information.

Any study on sexuality in Africa is subject to some limitations because discussion on sexual matters is a taboo in many African settings. The first limitation is that data collected were based on selfreporting and there was no method that was used to verify the responses. This limitation was minimized in the survey by asking about opinion of respondents rather than their personal experiences. The second limitation is that the in-depth interviews were conducted to only Black people whose main home language is Setswana. So opinion of other ethnic groups residing in Mahikeng is not reflected. We take note of these limitations when interpreting the findings.

Table I presents the socio-demographic characteristics of the respondents. The findings revealed that the chunk of the respondents dwell in the rural areas. The age distribution shows that women are fairly distributed in all age groups with a mean of 34.5 years. As expected, Setswana is the major language people speak at home $(66 \%)$. The table also shows that $51 \%$ of the respondents had primary or no education. Occupational distribution reveals that well over a quarter of the respondents were unemployed, the next category being government employees (24\%). Examination of the type of union shows that civil marriage is the most popular followed by traditional marriages. Cohabiting women forms the lowest percentage of the respondents (17\%). In terms of religious affiliation, the majority of the respondents are Christians. Despite the fact that most of the respondents are Christians, only $20 \%$ of the union is contracted under religious rite. About two-thirds of the respondents have been in a relationship for nine years or less and the mean duration of relationships is close to 9 years. The majority of respondents $(87 \%)$ have living children.

Table I: The percentage distribution of respondents by socio-demographic characteristics

\begin{tabular}{|c|c|c|}
\hline Characteristics & $\mathbf{N}$ & $\%$ \\
\hline \multicolumn{3}{|l|}{ Residence } \\
\hline Rural & 445 & 78.3 \\
\hline Urban & 123 & 21.6 \\
\hline \multicolumn{3}{|l|}{ Age group } \\
\hline$<25$ & 63 & 11.1 \\
\hline $25-29$ & 108 & 19.0 \\
\hline $30-34$ & 114 & 20.1 \\
\hline $35-39$ & 120 & 21.1 \\
\hline $40-44$ & 89 & 15.7 \\
\hline $45-49$ & 74 & 13.0 \\
\hline $\bar{x} \pm \sigma$ & 34.45 & 7.96 \\
\hline \multicolumn{3}{|l|}{ Home language } \\
\hline Setswana & 376 & 66.2 \\
\hline Afrikaans & 21 & 3.7 \\
\hline IsiXhosa & 50 & 8.8 \\
\hline Sesotho & 74 & 13.0 \\
\hline Zulu & 47 & 8.3 \\
\hline \multicolumn{3}{|l|}{ Type of union } \\
\hline Civil & 212 & 37.3 \\
\hline Religion & 112 & 19.7 \\
\hline Traditional & 149 & 26.2 \\
\hline Cohabiting & 95 & 16.7 \\
\hline \multicolumn{3}{|c|}{ Highest educational level } \\
\hline No education & 112 & 19.7 \\
\hline Primary & 179 & 31.5 \\
\hline Secondary & 156 & 27.5 \\
\hline Tertiary & 121 & 21.3 \\
\hline \multicolumn{3}{|l|}{ Occupation } \\
\hline Unemployed & 165 & 29.0 \\
\hline Business/trading & 80 & 14.1 \\
\hline
\end{tabular}




\begin{tabular}{llr} 
Government worker & 134 & 23.6 \\
Teaching & 59 & 10.4 \\
Student & 47 & 8.3 \\
Domestic worker/security & 83 & 14.6 \\
Religion & & \\
Roman Catholic church & 72 & 12.7 \\
Methodist & 146 & 25.7 \\
Pentecostal & 213 & 37.5 \\
Seventh Day Adventist & 95 & 16.7 \\
Other religion & 42 & 7.4 \\
Duration of union & & \\
$<5$ & 229 & 40.3 \\
$5-9$ & 145 & 25.5 \\
I0-I4 & 88 & 15.5 \\
I5-I9 & 31 & 5.5 \\
$20+$ & 75 & 13.2 \\
$\bar{x} \pm \sigma$ & 8.72 & 7.63 \\
Number of living children & & \\
None & 77 & 13.6 \\
I-2 & 290 & 51.1 \\
$3-4$ & 168 & 29.6 \\
$5+$ & 33 & 5.8 \\
Total & 568 & 100.0 \\
\hline
\end{tabular}

Source: Mahikeng Sexual and Reproductive Health Survey, 2012.

Note: Other religions include traditionalist and other religious affiliations whose sample was too small to stand alone in the analysis.

The age range of the IDls respondents is between 26 and 46 years. About $64 \%$ have been married for less than 10 years. Fifty-five percent of them have primary or no education. Slightly above half of respondents (52\%) are employed and $61 \%$ reside in the rural areas.

\section{Results}

\section{Knowledge of sexually transmitted infections and use of preventive measures}

Table 2 presents the knowledge of STls and use of preventive controls. Almost all respondents (99\%) have heard of STIs and HIV/AIDS (97\%). And the majority (95\%) of respondents knows that sexual intercourse is one of the modes of HIV transmission and STls can be prevented by using a condom (91\%). In addition, most of the respondents (90\%) know that STls are a risk factor for HIV. It seems married women in Mahikeng are well aware of the existence of STls in general and HIV/AIDS in particular. Other types of STls are not so familiar. Television and radio are the main source of information. However there is a mismatch between knowledge and practice. Majority of married women know that the mode of HIV transmission is through sexual intercourse and many know that condom can be used to prevent STIs, only $58 \%$ of respondents ever suggested use of condom to their partners and only $16 \%$ are currently using condoms. The main reason for not using condoms is that the respondent and the husband/partner trust each other $(60 \%)$. But there are cases where either the respondent opposes using condoms (38\%) or the husband / partner opposes (44\%). These reasons are very problematic hence a need for advocacy programmes.

Table 2: The percentage distribution of women by knowledge and attitudes toward STIs and preventive controls

\begin{tabular}{|c|c|c|}
\hline $\begin{array}{l}\text { Knowledge and attitudes } \\
\text { toward STls }\end{array}$ & $\mathbf{N}$ & $\%$ \\
\hline \multicolumn{3}{|l|}{ Ever heard of STIs } \\
\hline Yes & 561 & 98.8 \\
\hline \multicolumn{3}{|l|}{ STIs is a risk factor for HIV } \\
\hline Yes & 510 & 89.8 \\
\hline \multicolumn{3}{|l|}{ Types of STIs heard* } \\
\hline HIV/AIDS & 542 & 97.1 \\
\hline Gonorrhoea & 282 & 50.1 \\
\hline Candidiasis & 161 & 28.9 \\
\hline Herpes & 164 & 29.4 \\
\hline Syphilis & 279 & 50.0 \\
\hline \multicolumn{3}{|l|}{ Source of information* } \\
\hline Radio & 512 & 91.1 \\
\hline TV & 545 & 97.0 \\
\hline Newspaper & 367 & 65.3 \\
\hline Posters & 290 & 51.6 \\
\hline Partners & 166 & 29.5 \\
\hline Others (clinics, Doctors, nurses) & 185 & 32.9 \\
\hline \multicolumn{3}{|l|}{ Aggregate knowledge of HIV } \\
\hline Comprehensive knowledge & 188 & 33.9 \\
\hline Moderate & 336 & 60.5 \\
\hline Little & 23 & 4.1 \\
\hline None & 8 & 1.4 \\
\hline \multicolumn{3}{|c|}{ Currently using condom with partners } \\
\hline Yes & 92 & 16.2 \\
\hline \multicolumn{3}{|c|}{ Reasons for not currently using condoms* } \\
\hline Husband/partner opposed & 177 & 44.2 \\
\hline Respondent opposed & 150 & 37.5 \\
\hline Not accessible & 16 & 4.0 \\
\hline Sterile & 61 & 15.2 \\
\hline We trust each other & 240 & 60.0 \\
\hline Am afraid of my partner & 17 & 4.2 \\
\hline
\end{tabular}

Source: Same as Table I.

Note: * Respondents were allowed to state more than one condition. 


\section{Control and attitude over sexual issues}

Table 3 presents the distribution of women's control and attitude over sexual issues. Whilst $81 \%$ of respondents reported that a married woman can demand sex from her partner, $59 \%$ asserted that a woman can reject sexual intercourse. For those who approved that a woman can demand sex, an overwhelming majority (93\%) reported that it is just natural to do so. In addition, about half of them reported that a woman should demand sex in order to satisfy the husband and a quarter reported that a woman should demand sex when a/another child is needed. The reasons given for a woman to reject sexual intercourse from her husband are many that a woman should reject sexual intercourse if the husband beats her, if she is ill or if she suspects that the husband has an STI. Three-quarters or more reported that a woman should reject sex if she is not in the mood, if she knows that the husband has extramarital affairs, if she is menstruating, or if he does not support her.

Table 3: The percentage distribution of women's control and attitude over sexual acts

\begin{tabular}{lcc}
\hline Evaluation criteria & N & $\%$ \\
\hline Can women demand for sex? & & \\
No & 107 & 18.8 \\
Yes & $46 \mathrm{I}$ & 81.2 \\
Condition women can demand sex* & & \\
It is natural & 427 & 92.6 \\
To satisfy the husband & 249 & 54.0 \\
When another child is need. & 116 & 25.2 \\
Can women reject sexual intercourse? & \\
No & 234 & 41.2 \\
Yes & 334 & 58.8 \\
Conditions women can reject sex* & & \\
He beats her & 306 & 91.6 \\
She is ill & 302 & 90.4 \\
She suspect he has sexually & 301 & 90.1 \\
transmitted infection & & \\
He has sex outside marriage & 255 & 76.3 \\
(Cheats) & & \\
She is not in the mood & 252 & 75.4 \\
During menstruation & 249 & 74.6 \\
He does not support her & 241 & 72.2 \\
He does not support the children & 211 & 63.2 \\
He is drunk & 206 & 60.2 \\
\hline
\end{tabular}

\begin{tabular}{lcc}
\hline She does not want to get pregnant & 181 & 54.2 \\
During breastfeeding & 135 & 40.4 \\
During pregnancy & 71 & 21.3 \\
\hline
\end{tabular}

Source: Same as Table I.

Note: * Respondents were allowed to state more than one condition.

\section{Multivariate analysis of the factors related to sexual control}

The respondents in the study demonstrated variations in their ability to demand or reject sex by background characteristics. However, it is still not clear how these variables influence the respondents' sexual control in a multivariate perspective. Therefore, as stated in the 'methods' section, the binary logistic regression analysis is used for this purpose. Table I presents the distribution of all variables and number of cases for their corresponding categories used in this analysis. Two other variables were selected from Table 2 namely aggregate knowledge of HIV and currently using condom with husband/partner.

Table 4 presents the odds ratios and standard errors of two parsimonious binary logistic regression models. The two dependent variables are can demand sex and can reject sex. The models examine opinion of married women to sexual control. Of the independent variables selected, age, type of union, education and number of living children were found to be significantly related to the respondents' opinion for women to demand sex. Women who had tertiary education were more likely to approve a woman to demand sex than women without education. Women who were 40 years old or over were less likely to approve married women to demand sex than those aged 24-29. And respondents who were traditionally married and those who had five or more living children were less likely to approve that married women can demand sex compared to those without living children. The findings also show that women who were having traditional/customary marriage were less likely to suggest that a woman can demand sex from her husband compared to those with civil marriages. 
Table 4: The parsimonious logistic regression model showing the factors related to attitude towards woman demanding or rejecting sex from her partner

\begin{tabular}{|c|c|c|c|c|}
\hline \multirow[b]{2}{*}{ Variable } & \multicolumn{2}{|c|}{ Can demand sex } & \multicolumn{2}{|c|}{ Can reject sex } \\
\hline & Odds Ratio & SE & Odds Ratio & SE \\
\hline \multicolumn{5}{|l|}{ Age } \\
\hline$<25$ & 3.716 & 0.811 & $0.414 *$ & 0.450 \\
\hline $25-29(\mathrm{RC})$ & 1.000 & 1.000 & 1.000 & 1.000 \\
\hline $30-34$ & 0.902 & 0.417 & 0.837 & 0.354 \\
\hline $35-39$ & 0.528 & 0.406 & $0.37 I^{* *}$ & 0.365 \\
\hline $40-44$ & $0.377^{*}$ & 0.445 & $0.55 \mathrm{I}$ & 0.419 \\
\hline $45-49$ & $0.346 *$ & 0.447 & 0.597 & 0.429 \\
\hline \multicolumn{5}{|l|}{ Type of Union } \\
\hline Civil (RC) & 1.000 & 1.000 & 1.000 & 1.000 \\
\hline Religion & 0.694 & 0.336 & 1.166 & 0.313 \\
\hline Traditional & $0.296 * *$ & 0.296 & 0.686 & 0.271 \\
\hline Cohabiting & 0.539 & 0.413 & $0.269 * *$ & 0.338 \\
\hline \multicolumn{5}{|l|}{ Education } \\
\hline None (RC) & 1.000 & 1.000 & 1.000 & 1.000 \\
\hline Primary & 1.396 & 0.334 & $5.742 * *$ & 0.318 \\
\hline Secondary & 1.699 & 0.530 & $8.137 * *$ & 0.346 \\
\hline Tertiary & $2.073^{*}$ & 0.729 & II.932** & 0.511 \\
\hline \multicolumn{5}{|l|}{ Occupation } \\
\hline Unemployed (RC) & - & - & 1.000 & 1.000 \\
\hline Business/ Trading & - & - & $2.605^{* *}$ & 0.333 \\
\hline Government worker & - & - & $3.375^{* *}$ & 0.394 \\
\hline Teaching & - & - & $4.331 *$ & 0.592 \\
\hline Student & - & - & $4.178^{* *}$ & 0.467 \\
\hline Domestic worker & - & - & $2.029 *$ & 0.320 \\
\hline \multicolumn{5}{|c|}{ Number of living children } \\
\hline None (RC) & 1.000 & 1.000 & 1.000 & 1.000 \\
\hline $\mathrm{I}-2$ & 0.601 & 0.556 & $\mathrm{I} .356$ & 0.386 \\
\hline $3-4$ & 0.562 & 0.586 & 0.729 & 0.448 \\
\hline $5+$ & $0.262 *$ & 0.684 & $0.270 *$ & 0.668 \\
\hline Constant & $14.107^{* *}$ & 0.640 & $0.298 *$ & 0.511 \\
\hline
\end{tabular}

Source: Same as Table I

Note: * significant at 0.05 level; ** significant at 0.0 I level; - not significant;

SE standard errors; and RC reference category

All the significant variables are related to approval for demand for sex in the expected direction. Older women, those with traditional marriages, less educated and those with large family sizes were more likely to feel inferior and abide to traditional customs and beliefs which are discussed below. This has negative implication on their attitude to demand sex.

The variables that are significantly related with the respondent reporting that a woman can reject sexual intercourse include age, type of union, education, occupation, and number of living

children. Women who were below 25 years old and those aged 35-39 were less likely to report that women can reject sex compared to women aged 24-29. Cohabiting women were less likely to report that a woman can reject sex from her husband/partner compared with women who had civil marriages. It is not surprising for cohabiting women to disapprove a woman rejecting sex as their relationship is not very secure. As expected, the higher the educational level the more likely the respondent approved a woman can reject sex. Women who were doing any type of work or 
students were more likely to approve rejecting sex than women who were unemployed. Women with five or more living children were less likely to reject sex than those without a living child. Whilst occupation was only significant in the 'reject sex' model, age and type of union gave a different picture. The pattern depicted for age is not very clear. However, aggregate knowledge of HIV and condom use were neither significant in the 'demand sex' model nor in the 'reject sex' model.

\section{Findings from the qualitative study}

The general views portray that social and cultural atmosphere still influence the disposition of most women on the issue of demanding or rejecting sex from their husbands/partners. Their opinion on rejecting sex is influenced by cultural belief that husbands have right to sex, religious belief and consequences of rejecting sex. With such strings attached to women's sexuality, their attitude to sexual control is embedded in fear of losing their husbands/partners.

Women were asked how their culture affects their ability to reject sexual advances from their husband. Over half responded that their culture does not support them to reject sex from their husband. However a quarter of them claimed that their culture supports them to reject sex from their husbands especially when a woman has a new-born baby. In other words, a woman cannot just reject sex from her husband without a valid reason. Below are some of the responses of the participants on their ability to reject sex from their husbands.

Woman can reject sex, but it has some consequences like rape, physical abuse, divorce, cheating, patronizing commercial sex workers and polygamy etc (urban woman, aged 39, married 10+ years)

From human rights perspectives, I have the right to reject sex from my husband. But the Bible says husbands and wives should not deny one another sex except when they are fasting (urban woman, aged 37, married 7 years)

Yes, I have the right to reject sex, but our culture disagrees with that. Nowadays the law can protect you. If you take the matter to court that he forces you to have sex, it will be a different story. But I will not take my husband to court I love him (laugh) (urban woman, aged 29 , married 5 years)

According to the society you are not supposed to refuse sex from your husband and my culture does not support me as he is my husband who has fulfilled cultural requirements for marriage (rural woman, aged 44 , married $10+$ years)

No, when he wants it (sex) nobody will stop him even if it is red (menstruating) he does not care. I know it belongs to him, he got right to have it anytime, unless he shares me with somebody, so I think I have no right over sex to him (rural woman, age 28, married 9 years)

Most women have greater ability to demand sex from their husbands. Majority responded that there is nothing wrong for a woman to demand sex from the husband except if there are marital problems. However few respondents reported that culture is set back to their ability to demand sex. For a woman to demand sex suggests she is not cultured. Below are the responses of the participants on the influences of culture on their ability to demand sex from their husbands.

For a married woman to demand for sex, your husband and family can regard you as disrespectful wife. They will call you names along the lines of being a slut. (rural woman, aged 42, married $10+$ years)

Yes I demand sex if am not getting it. Usually it is us women who are often tired and would deny the men sex. If am in the mood for sex and it has not been happening, I will tell him and make sure I get it (Urban woman, aged 35, married 9 years)

Culturally a woman is taught how to make her husband happy sexually. You are taught about sex and other important things in marriage during initiation. We do not demand sex but you seduce him. Men would not miss opportunity for sex (laughter) (rural woman, aged 46, married $10+$ )

The reason why I should demand sex is for my man to be secured. Men are very insecure. He may think you are getting it somewhere if you do not ask. (urban woman, aged 31 , cohabiting for 6 years) 
Women were asked if they consider themselves at risk of contracting STls. Most of the women were of the opinion that marriage still accord protection against STls. This view is consistent with Langen (2005) findings that marriage is a safe haven for STls. About two-thirds did not consider themselves at risk because they trust each other, one-fifth considered themselves to be at risk and only one-tenth said they always use a condom. Some of the responses of the participant are

My husband does not show me any sign not to trust him (urban woman, aged 34, married 10+ years)

I see myself at risk as men are not trustworthy and my husband is working outside Mahikeng (rural woman, aged 35 , married 8 years)

Yes, as men are not trustworthy, you will never know what they do when they are out there (rural woman, aged 31 , married $10+$ years)

The quantitative results concur with the findings of the qualitative study on the use of condom. On the question about how do you feel about asking your husband to use a condom, about two-thirds said they can ask comfortably. A few responded they are currently using condom. Women can ask their husbands to use condom but it remains unknown whether the husband can accept the request. In addition, women were afraid of accusation of infidelity if they suggest condom use. Some of the reasons for the inability to ask include:

It is going to be a battle (asking to use a condom) as we never used it for a long time (rural woman, aged 28, married 7 years)

Because we did not use it from the beginning, it is a bit difficult, because he will ask me why all of a sudden I want to use it. I trust him and he trusts me as well. Because I have not dated anyone since I met him. But I know that men do cheat (urban woman, aged 32, married 8 years)

It is not easy. I can't. He will think that I am cheating (rural woman, aged 28 , married 6 years)

I have never asked him, he uses a condom when he wants (rural woman, aged 43, married 10+ years)

\section{Discussion}

This study has examined the attitudes toward sexual control among women in marital or cohabiting relationships and what it portends for the control of HIV/AIDS. The level of control women have over their sexuality is the prerequisite of sexual and reproductive health decision-making outcomes. In general, the study indicates that women have considerable control over their sexuality. On operationalizing the dimension of sexual control, the overwhelming majority of the respondents approve demanding sex from their partners. The stand of women to demand sex because it is natural, to satisfy their partners and for procreation indicates a shift from societal norm of women passiveness in sexual and reproductive matters which contrast with previous studies in Uganda (Nyanzi et al., 2005). Women are socialized to satisfy their husbands sexually but not to express their desirability by demanding for sex. It is expected that older women, uneducated, those in traditional marriages and those with large families did not approve women to demand for sex. This inability to demand sex may be linked to the cultural socialization of married women to be submissive in sexual relations to their husbands or partners. This concurs with the evidence from the qualitative findings. It is obviously that culture plays out in the realms of older women, women with limited education, those who are traditionally married and those with large families.

The majority of the respondents asserted that a woman can reject sex from her husband/partner during menstruation, illness or when not in the mood. With no doubts there are circumstances under which sex cannot occur. The study to a good extent concurs with the report in Ghana (AwusaboAsare et al., 1993) where over four-fifth of women would reject sex with husbands known to suffer from sexually transmitted infections. The result differ with a recent report among Edo women in Nigeria who cannot reject sex because of the fear of been beaten (lyayi et al., 20I I). On the other hand, consistent with the conclusion of Wusu and IsiugoAbanihe (2008) that fear of been beaten is not a normative practice in marital relationship because of mutual respect. This suggests that women are not treated as sexual objects as earlier findings in women sexuality indicated. Indeed fear of violence may suppress the courage of women to exercise control over their sexuality.

Salient findings of the study are the influence of the nature of the union on the sexual control of a woman. Cohabitation has negative effects on a woman's sexual control ability which concur with the findings in Honduras (Speizer et al., 2005). 
Cohabitation is becoming a norm in South Africa, but the consciousness that it is void of cultural recognition subjugates the ability of the woman to reject sex. It is in the instinct that for a man and woman to be together and indulge in sexual activities, there are certain criteria to be met. Since cohabitation is devoid of such criteria, cohabiting women do not feel secured to exercising control over their sexuality.

Consistent with numerous findings (AwusaboAsare et al., 1993; Langen, 2005; Ogunjuyigbe \& Adeyemi, 2005; lyayi et al., 20II; Delbiso, 2013) women with socio-economic advantage exercise greater control over their sexuality compared to those who are socio-economically disadvantaged. The state of being uneducated and unemployed is the main factor that stifles the mandate of Mahikeng women over their sexuality. Such women always nurture the fear of losing their husbands to other women which may aggravate their state of poverty and hopelessness. The impact of economic dependence is corroborated with the qualitative findings where a considerable percentage of women agreed that depending on husbands for support deterred them from exercising their sexual control to avoid some domestic sanctions. Even in cultural discretion, there are some circumstances where women have some right to refuse sex. However, it is uncertain that such right could exist among women who have no source of income coupled with their state of being uneducated. The absolute dependence of women on their partner for support presents a massive impediment on their attitude to sexual control. This has some implication in the control of HIV/AIDS in Mahikeng.

It is apparent that the respondents have knowledge of STls mode of transmission, STls as risk factor for HIV and condom use prevents STIs. However, the magnitude of the knowledge on issues of STls cannot be equated on condom usage as it should be among people concerned about health risks. This finding is consistent with the low prevalence of condom use among married and cohabiting couples reported in KwaZulu-Natal, South Africa (Maharaj \& Cleland, 2004; Langen, 2005) and elsewhere (lyayi et al., 20I I; Nyanzi et al., 2005). Apart from women who reported personal dislike and husband opposition to condom use, a greater majority do not use because of trusting their partners. One of the major challenges in the research on sexual control is the quantification of sexual trust in marital or cohabiting relationships. The high prevalence of HIV/AIDS and other STIs among married women compared to single women, appeals for the verification of sexual trust in marital or cohabiting relationships.

It is not clear to what extent fear is confused with trust. We have no doubt that fear is translated into trust at best. From the qualitative findings, woman lamented that failure to initiate condom use from the beginning has affected their courage to ask for it currently despite suspicion of infidelity and at risk of being infected. Some women have never asked their husband to use condom because their husbands use when they want. A similar attitude of whether to use condom or not is always up to the men was document by Mantell et al. (20II). We have no doubts that the inability of women to exercise control over their sexuality have translated to the art of trusting their partners. This kind of blithe attitude to self-protection gives men leverage over women's in sexual arena and may bear heavily in the spread of HIV in steady relationships. Ogunjuyigbe and Adeyemi (2005) noted that women lamented that men have not changed their sexual attitudes and are very reluctant to use condom. Previous studies were conducted in a setting that may be considered to have lower HIV prevalence compared to South Africa (UNAIDS, 20I0) where condom use is low on the premises of trust on partner. We posit that the trust women have on their husband or partner may have some implications on the spread of HIV/AIDS in South Africa.

Indeed, Mahikeng women who participated in the study have demonstrated considerable control over their sexuality, in addition to knowledge of HIV prevention. This is consistent with the findings in KwaZulu-Natal, women are not powerless to take preventive measure when infection looms in the relationship (Maharaj \& Cleland, 2004). However, the attitude of women to HIV preventive measures is disturbing having demonstrated good knowledge about mode of infection and prevention. In South Africa, the spread of HIV/AIDS is through unprotected sex. Thus the major restriction to safer sex practices is defined within the sexual relationship and the conduct of the women (Worth, 1989; Dixon-Mueller, 1993). What stood out clearly in the study is that education, economic empowerment and the nature of the union are critical determinants of women's mandate over their sexual control. The present study suggests that vulnerability of women 
to STIs including HIV may be linked to their attitude to sexual control and negligence of preventive measures. The use of condom does not show good potentials for curbing HIV infection among women in marital or cohabiting union in Mahikeng.

\section{Conclusion and Recommendations}

Knowledge of STls including HIV is very high among married women in Mahikeng, South Africa. However, use of condoms is very low. It is striking to note that married women themselves disapprove of the use of condoms because they believe that there is a high degree of trust with their husbands/partners. This finding has a lot of implications especially because, as noted above, the proportion of married women living with HIV is increasing dramatically. But there are women who are willing to use condoms however non receptiveness of condom by their husbands/partners remains a challenge. The intervention programmes meant to educate both men and women on the risk they are taking not to use condoms will go a long way in combating HIV/AIDS.

On the issue of sexual control, it is encouraging to find out that most married women approve demand for sex from their husbands/partners and they report that it is just natural to do so. However, a significant proportion of married women do not approve that married women can reject sexual intercourse with their husband/partner under any circumstances. This is the group of women that needs serious consideration in terms of policy. It boils down to empowering married women to have control over their sexuality. This is confirmed by the variables found to be significant in the multivariate analysis. It seems there is still room for the South African government in general and the North-West provincial government in particular to continue addressing the issue of improving status of women. Addressing the specific issues affecting the women's status in their locale requires programme of empowerment through job provision. Since it is clear that having income gives women an edge in sexual control, there is need for informal training with the aim to give them employment. It should be noted also that married women should not be taken for granted when it comes to sexual and reproductive health services as the focus in the past has only been to young and unmarried women and men.

\section{Acknowledgement}

We would like to thank the Research Niche Area 'Population and Health' of the North West University (Mafikeng Campus) for supporting this research.

\section{References}

Ackermann, L. \& de Klerk, G.W. (2002) Social factors that make South African women vulnerable to HIV infection. Health Care for Women International 23:2, 163-172.

Awusabo-Asare, K., Anarfi, J.K. \& Agyeman, D.K. (1993) Women's control over their sexuality and the spread of STDs and HIV/AIDS in Ghana. Health Transition Review3 I-I4.

Balmer, D.H., Gikundi, E., Kanyotu, M. \& Waithaka, R. (1995) The negotiating strategies determining coitus in stable heterosexual relationships. Health Transition Review 5, 85-95.

Coombs, R.W., Reichelderfer, P.S. \& Landay, A.L. (2003) Recent observations on HIV type-I infection in the genital tract of men and women. AIDS 17, 455-480.

Delbiso, T.D. (20|3). Gender power relations in reproductive decision-making: The case of Gamo migrants in Addis Ababa, Ethiopia. African Population Studies, 27(2): I 18-126.

Department of Health (20II) National Antenatal Sentinel HIV and Syphilis Prevalence Survey in South Africa, 2010 - 20II. Republic of South Africa, Pretoria.

Dixon-Mueller, R. (1993) The sexuality connection in reproductive health. Studies in Family Planning 24, 269-282.

Folbre, N. (1986) Hearts and spades: paradigms of household economics. IDS Bulletin 22, 5I-59.

Glynn, J.R., Caraël, M., Auvert, B., Kahindo, M., Chege, J., Musonda, R., Kaona, F. \& Buvé, A. (200I) Why do young women have a much higher prevalence of HIV than young men? A study in Kisumu, Kenya and Ndola, Zambia. AIDS I5, 5I-60.

Gulbrandsen, Ø. (1986) To marry or not to marry: marital strategies and sexual relations in a Tswana society. Ethnos, 5I(I): 7-28.

Hargreaves, J.R., Linda, A., Morison, L. A., Kim, J.C., Busza, J., Phetla, G., John, D.H., Porter, Watts, C., \& Pronyk, P. M. (2009) Characteristics of sexual partnerships, not just of individuals, are associated with condom use and recent HIV infection in rural South Africa, AIDS Care: 
Psychological and Socio-medical Aspects of AIDS/HIV2 I (8), I058-I070.

lyayi, F. Igbinomwanhia, O., Bardi, A. \& lyayi, O. (20II) The control of Nigerian women over their sexuality in an era of HIV/AIDS: A study of women in Edo State in Nigeria. International NGO Journal 6, II3-121.

Jerrett, M.D. (1994) Parents' experience of coming to know the care of a chronically ill child. Journal of Advanced Nursing 19, 1050-1056.

Jewkes, \& Morrell, R. (2010) Gender and sexuality: emerging perspectives from the heterosexual epidemic in South Africa and implications for HIV risk and prevention. Journal of the International AIDS Society 1 3, 6 .

Jewkes, R., Penn-Kekana, L., Levin, J., Ratsaka, M. \& Schrieber, M. (1999) He must give me money, he mustn't beat me. Violence against women in three South African provinces. CERSA (Women's health). Medical Research Council, Pretoria.

Langen, T. (2005) Gender power imbalance on women's capacity to negotiate self-protection against HIV/AIDS in Botswana and South Africa. African Health Sciences 5, I88-197.

Magadi, M.A. (20II) Understanding the gender disparity in HIV infection across countries in subSaharan Africa: evidence from the Demographic and Health Surveys. Sociology of Health \& Illness 33, (4), 522-539.

Mogale, R.S., Burns, K.K. \& Richter, S. (20/2) Violence Against Women in South Africa: Policy Position and Recommendations. Violence Against Women 18(5), 580-594.

Maharaj P. \& Cleland, J. (2004) Condom use within marital and cohabiting partnerships. Studies in Family Planning 35, I 16-124.

Mantell, J.E., West, B.S., Sue, K., Hoffman, S., Exner, T.M., Kelvin, E. \& Stein, Z. (20II) Health care providers: a missing link in understanding acceptability of the female condom. AIDS Education Preview 23, 65-78.

Mathews, S. \& Abrahams, N. (200I) Combining stories with numbers: An analysis of the impact of the Domestic Violence Act (No. 116 of 1998) on women. The Gender Advocacy Programme and the Medical Research Council's Gender and Health Research Group, Cape Town.

Matshidze, K.P., Richter, L.M., Elison, G.T.H., Levin, J.B. \& Mclntyre, J.A. (1998) Caesarean section rates in South Africa: Evidence of bias among different population groups. Ethnicity and Health 3, 7I-79.

McElroy, M.B. (1990) The empirical content of Nash-bargained household behavior. Journal of Human Resources 25, 559-583.

Mindry, D., Maman, S., Chirowodza, A., Murvha, T., van Rooyen, H., \& Coates, T. (20II) Looking to the future: South African men and women negotiating HIV risk and relationship intimacy. Culture, Health \& Sexuality 13 (5), 89 - 602.

Morrell, R. (1998) Of boys and men: Masculinity and gender in southern Africa. Journal of Southern African Studies 24, 605-629.

Nkomazana, F. (2008) The experiences of women within Tswana cultural history and its implications for the history of the church in Botswana. Studia Historiae Ecclesiasticae 34(2), 83-I I6.

Nyanzi, B., Nyanzi, S., Wolff, B. \& Whitworth, J. (2005) Money, men and markets: Economic and sexual empowerment of market women in southwestern Uganda. Culture, Health \& Sexuality 7, 13-26.

Odebode, O. (2004) Husbands are crowns: Livelihood pathways of low-income urban Yoruba women in Ibadan, Nigeria. Unpublished $\mathrm{PhD}$ thesis. Institute of Social Studies, The Hague.

Ogunjuyigbe, O.P. and Adeyemi, O.E. (2005) Women's sexual negotiation within marital/cohabiting union: Implication for HIV/AIDS infection and control in a metropolitan city. Demographic Research 12, 29-50.

Omeje, J. C., Oshi, S.N. \& Oshi, D. (20II) Does possession of assets increase women's participation in reproductive decision-making? Perception of Nigeria women. Journal of Biosocial Science 43, I0I-I I I.

Orisaremi, T.C. \& Alubo, A. (2012) Gender and Reproductive Rights to Tarok Women in Central Nigeria. African Journal of Reproductive Health, 16(I), 83-96

Orubuloye, I.O., Caldwell, J.C. \& Caldwell, P. (1993) African women's control over their sexuality in an era of AIDS. Social Science and Medicine 37, 859-872.

Osuafor, G.N. (2014) Decision-making on sexual and reproductive health issues among women in heterosexual relationships in Mahikeng, South Africa. Unpublished doctoral dissertation, NorthWest University (Mafikeng Campus), Mahikeng, South Africa. 
Peart, N.S. (1983) Civil or Christian marriage and customary unions: the legal position of the discarded' spouse and children. The Comparative and International Law Journal I6(I), 39-64.

Phyllis, D. (2013) "Safer sex talk". Negotiating safer sex practice in heterosexual relationships. Mediterranean Journal of Social Science 4, 2.

Schoepf, B.G. (1992) Women at risk: Case studies from Zaire. Herdt, G. \& Lindenbaum, S. (eds.) In the Time of AIDS - Social Analysis Theory and Method. Sage, London, pp. 259-286.

Speizer, I.S., Whittle, L. \& Carter, M. (2005) Gender relations and reproductive decision making in Honduras. International Family Planning Perspectives 31, I-I3.

Statistics South Africa (2012) Population Census of South Africa: Census demarcation 20I I. Statistics South Africa, Pretoria.

Swart-Kruger, J. \& Richter, L. (1997) AIDS-related knowledge, attitudes, and behavior among South African street youth: Reflections on power, sexuality and autonomous self. Social Science and Medicine 45, 957-966.
UNAIDS (2010) Report on the Global Aids Epidemic 2010. Joint United Nations Programme on HIV/AIDS, Geneva.

Varga, C.A. (2003) How gender roles influence sexual and reproductive health among South African adolescents. Studies in Family Planning 34, 160-172.

Varga, C.A. \& Makubalo, E.L. (1996) Sexual noncontrol. Agenda 28, 3I-38.

Wodi, B.E. (2005) Gender Issues in HIV/AIDS Epidemiology in Sub-Saharan Africa. State University of New York, College at Cortland, Wagadu Volume 2.

Worth, D. (1989) Sexual decision-making and AIDS: Why condom promotion among vulnerable women is likely to fail. Studies in Family Planning 20, 297-307.

Wusu, O. \& Isiugo-Abanihe, U.C. (2008) Understanding sexual negotiation between marital partners: A Study of Ogu families in Southwestern Nigeria. African Population Studies 23, 155-I7I. 